\title{
Anti-eczema Mechanism of Action of Nigella sativa for Atopic Dermatitis: Computer-aided Prediction and Pathway Analysis Based on Protein-chemical Interaction Networks
}

\author{
Meidyta Sinantryana Widyaswari ${ }^{1}$, Iis Noventi ${ }^{2}$, Herdiantri Sufriyana ${ }^{3,4^{*}}$ \\ ${ }^{1}$ Department of Dermatology and Venereology, College of Medicine, University of Nahdlatul Ulama Surabaya, Indonesia \\ ${ }^{2}$ Department of Medical-Surgical Nursing, College of Nursing and Midwifery, University of Nahdlatul Ulama Surabaya, \\ Indonesia \\ ${ }^{3}$ Department of Medical Physiology, College of Medicine, University of Nahdlatul Ulama Surabaya, Surabaya, Indonesia \\ ${ }^{4}$ Graduate Institute of Biomedical Informatics, College of Medical Science and Technology, Taipei Medical University, \\ Taipei, Taiwan
}

\section{A R T I C L E I N F O}

\section{Article history:}

Received 26 August 2019

Received in revised form 14

October 2019

Accepted 21 October 2019

Available online 31 October 2019

Keywords:

Nigella sativa,

atopic dermatitis,

protein-chemical interaction

networks,

PASS.

*) Corresponding author:

herdiantrisufriyana@unusa.ac.id

\begin{abstract}
A B S T R A C T
Introduction: Black cumin (Nigella sativa) is widely used to treat various diseases. It is also believed to relief skin conditions accompanied by itching symptom, such as atopic dermatitis (AD) or eczema. However, the anti-eczema mechanism of action is still unclear. The aims of this syudy was to identify anti-eczema mechanism of action of $N$. sativa for $\mathrm{AD}$ using computer aided prediction and pathway analysis based on protein-chemical networks.

Methods: We utilized dataset consisting chemical compounds of $N$. sativa from KNApSAcK. It is a comprehensive species-metabolite relationship database. Using canonical SMILES strings that encode molecular structures of each compound, we predicted the probabilities of activity ( $\mathrm{Pa}$ ) for anti-eczema effect based on PASS algorithms. The compounds with $\mathrm{Pa}>0.7$ were included for pathway analysis based on protein-chemical interaction networks in STITCH database. We selected interactomes built by experimental data, gene co-expression, closest gene position, fusion, cooccurence, computational prediction, and other secondary data.

Results: Thirty-five active compounds of $N$. sativa have been utilized and 19 of them have potential anti-eczema effects. Oleic acid and lauric acid were predicted with Pa-value of 0.947 and 0.920 for anti-eczema effect, respectively. However, only lauric acid was confirmed having a plausible mechanism of action via LY96-TLR4- PIK3R1 pathway for lipopolysaccharide receptor activity (false discovery rate $[\mathrm{FDR}]=0.0243$ ) and low-density lipoprotein particle receptor binding (FDR $=0.0118$ ).

Conclusion: Lauric acid in N. sativa has potential antieczema effect to prevent relaps in AD patients by controlling opportunistic bacterial infection that aggravates itching symptom in this condition.
\end{abstract}

\section{Introduction}

Atopic dermatitis (AD), or eczema, is a chronic, recurrent skin inflammation accompanied by severe itching and dry skin on certain area of skin predilection. It commonly occurs at early childhood and relapse at adulthood. Ten percent of the cases may last up to adolescence or adulthood. Prevalence of AD varied among countries, which have increased worldwide, especially in industrialized countries. The prevalence was $10-20 \%$ in children, while it was $1-3 \%$ in adults. This multifactorial disease has unclear etiopathogenesis, but it generally involves complex interactions of skin barrier function, immune system disorders, genetics, and other factors, including environment, diet, infection, and stress. ${ }^{1}$

Mismanagement of AD often occurs because of its similarity to other chronic skin diseases. This disease commonly occurs in primary care. ${ }^{2}$ As a chronic skin inflammatory disease, a primary choice of long-term treatment is topical drugs, particularly those with a steroid compound. Its use may not be acceptable for the patients who believe this as a chemical substance which is harmful for long-term use. In several cultures, particularly in Indonesia, it is widely accepted that medicinal plants are 
safe for long-term use. Black cumin is one of the medicinal plants. It may improve quality of life of the patients and reduce severity of the disease. ${ }^{3}$

Black cumin (Nigella sativa) is a plant that grows up to $20-90 \mathrm{~cm}$ in height, finely-separated leaves, and flowers with multiple colors. These are white, yellow, pink, pale blue and pale purple. Each flower consists 5-10 crowns. The large fruits contain several seeds. This plant is one of the most common medicinal plants that were investigated. It is because of its wide spectrum of applications in traditional medicine from many countries worldwide. The seeds are commonly used to treat various diseases. Most of the therapeutic effects are contributed by thymoquinone which is the main active ingredient in the seed's oil. Several studies have demonstrated that this plant could be used as an antidiabetic, anticancer, immunomodulator, pain reliever, antimicrobial, antioxidant, hepatoprotector, and others. ${ }^{4}$ However, an active substance of $N$. sativa, which has antieczema effect, is still unclear.

To perform a preclinical research efficiently, we need to conduct preliminary study identifying the active substance and its mechanism action. We utilized dataset of active compounds from a database of plants. A classification algorithm can be used to predict the antieczema effect based on a structure-activity relationship models derive from other chemical substances. The mechanism of action can be predicted by protein-chemical interactomes using over representation analysis. This study aims to identify active compounds of $N$. sativa, which have antieczema effect, and its mechanism of action for AD using computeraided prediction and pathway analysis based on proteinchemical interaction networks.

\section{Methods \\ Study design and data source \\ We applied a descriptive exploratory study design. This study utilized dataset from KNApSAcK database (http:// kanaya.naist.jp/KNApSAcK/) at April 13th, 2018. Active compounds' data of $\mathrm{N}$. sativa were retrieved without considering which parts of plant had been taken to identify these compounds. We only selected those which have available data in protein-chemical interaction database. In addition, these compounds should have canonical structure information as inferred from simplified molecular-input line-entry system (SMILES) in PubChem database (https:// pubchem.ncbi.nlm.nih.gov/).}

\section{Prediction of antieczema effect}

Selected compounds were predicted for their effects by quantitative structure-activity relationship (QSAR) modeling. We used prediction of activity spectra for substances (PASS) web application (http://pharmaexpert. $\mathrm{ru}$ /PASSonline) to apply its classification algorithm based on the QSAR model. This web application classified the selected compounds into several classification systems. We only looked for those that were classified by its pharmacological effect, particularly with probability of activity $(\mathrm{Pa})>0.7$ for antieczema.

\section{Pathway analysis to identify antieczema mechanism of action}

To identify mechanisms of action for these compounds, we used search tool for interacting chemicals (STITCH) platform (http://stitch.embl.de). By over representation analysis (ORA), this platform annotated the compounds with existing protein-chemical interactomes in STITCH database. We configured ORA to analyze the compounds based on experimental data, gene co-expression, closest gene position, gene fusion, co-occurence, computational prediction, and other secondary data. We configured interaction confidence to be 0.400 for the minimum value. Other parameter configuration was maximum 10 interactors for each layer up to the second interaction layer.

The platform also retrieved information gene ontology (GO) database for functional enrichment analysis. The information consisted of biological process, molecular function, and cellular component, which are involved in the interactomes. Individual GO information was used to identify which one was related to antieczema based on previous studies.

We also determined a gene set consisted of genes which involved in the antieczema interactomes. Pathway analysis was conducted by including this gene set with that related to AD based on previous studies. Eventually, this analysis identified antieczema mechanism of action in silico.

\section{Results}

Retrieved active compounds of Nigella sativa

Active compounds $N$. sativa were retrieved from KNApSAcK database (Table 1). Thirty-five active compounds were obtained. Although this database did not provide which parts of the plant that the compounds were identified, previous studies showed that thymoquinone was mostly identified in seed's oil., ${ }^{4,5}$

\section{The active compounds with antieczema effect}

The active compounds have been selected based on the criteria (Table 2). Nineteen of 35 active compounds have predicted antieczema effect with $\mathrm{Pa}$-value of $>0.7$ and available in protein-chemical interactomes of STITCH database. Six compounds on STITCH database were identical with those in PubChem database. Canonical SMILES codes of these compounds from PubChem were used as features to predict the antieczema effect. Oleic acid was a compound of $\mathrm{N}$. sativa that had highest biological activity is (Pa-value=0.947). However, pathway analysis showed that lauric acid had relevant antieczema effect with $\mathrm{Pa}$-value which was closest to that of oleic acid $(\mathrm{Pa}=0.920)$.

\section{Predicted antieczema mechanism of action}

Pathway analysis was conducted to identify antieczema mechanism of action (Figure 1). Several interactomes over-represented oleic acid and lauric acid. The interactomes included genes/transcripts/proteins coded by the gene name. These were FAAH, PMP2, RBP1, APOE, APOB, LDLR, PCSK9, GLTP, ALB, UBC, MTRNR2L2, LTB4R2, GPR68, LY96, TLR4 and FCGRT. In addition, the interactomes also included other chemical substances. Therefore, two of active compounds contained by $\mathrm{N}$. sativa were active substances that had been known having interactions with several proteins

To confirm which interactomes were related to the anti-eczema mechanism of action, functional enrichment analysis was carried out (Table 3). Majority of the GO information were related to cholesterol metabolism and interactions with lipopolysaccharides (LPS). Interaction 
with LPS was considered having a role in pathophysiology of AD because of LY96 and TLR4. Increasing transepidermal water loss, allergic sensitization, and thickness of epidermis were demonstrated on AD lesion of a mice model with TLR4 deficiency that had been exposed to allergen derived from Aspergillus fumigatus for 3 weeks.7 Oleic acid may also play a role in determining occurrence of $\mathrm{AD}$ via cholesterol metabolic pathway. Hyperlipidemia was found as comorbidity (10.35\%) in 30,354 patients with $\mathrm{AD}$ compared to those without $\mathrm{AD}{ }^{8}$

A gene set related to AD were determined based on a previous study.9 This consisted of LOR, KRT17, SPRR2D, SPRR1A, SPRR1B, IVL, CCR7, CCL19, PIK3R1, and
STAT1. These gene names along with LY96, TLR4, and lauric acid were analyzed by STITCH platform (Figure 2). Lauric acid, LY96, and TLR4 were over-represented by interactomes that were annotated as LPS detection for the biological process, LPS receptor activity for the molecular function, and LPS receptor complex for the cellular components. This was considered having a greater role in antieczema mechanism of action compared to other GO information related to cholesterol metabolism. The LY96 and TLR4 had interactions with MYD88 that connected them to AD via PIK3R1. The score was 0.576 for interaction of MYD88 and the gene set.

Table 1. Active compounds of Nigella sativa retrieved from KNApSAcK database.

\begin{tabular}{|c|c|c|}
\hline Active compounds & Molecular formula & Molecular weight (kD) \\
\hline Thymol & $\mathrm{C} 10 \mathrm{H} 14 \mathrm{O}$ & 150.1044651 \\
\hline Carvacrol & $\mathrm{C} 10 \mathrm{H} 14 \mathrm{O}$ & 150.1044651 \\
\hline alpha-Thujene & $\mathrm{C} 10 \mathrm{H} 16$ & 136.1252005 \\
\hline alpha-Pinene & $\mathrm{C} 10 \mathrm{H} 16$ & 136.1252005 \\
\hline beta-Pinene & $\mathrm{C} 10 \mathrm{H} 16$ & 136.1252005 \\
\hline Myrcene & $\mathrm{C} 10 \mathrm{H} 16$ & 136.1252005 \\
\hline Lauric acid & $\mathrm{C} 12 \mathrm{H} 24 \mathrm{O} 2$ & 200.17763 \\
\hline Oleic acid & $\mathrm{C} 18 \mathrm{H} 34 \mathrm{O} 2$ & 282.2558803 \\
\hline Anisaldehyde & $\mathrm{C} 8 \mathrm{H} 8 \mathrm{O} 2$ & 136.0524295 \\
\hline Apiol & $\mathrm{C} 12 \mathrm{H} 14 \mathrm{O} 4$ & 222.0892089 \\
\hline Estragol & $\mathrm{C} 10 \mathrm{H} 12 \mathrm{O}$ & 148.088815 \\
\hline Myristicin & $\mathrm{C} 11 \mathrm{H} 12 \mathrm{O} 3$ & 192.0786443 \\
\hline (+)-R-Citronellol & $\mathrm{C} 10 \mathrm{H} 20 \mathrm{O}$ & 156.1514153 \\
\hline p-Cymene & $\mathrm{C} 10 \mathrm{H} 14$ & 134.1095505 \\
\hline$(+)$-Fenchone & $\mathrm{C} 10 \mathrm{H} 16 \mathrm{O}$ & 152.1201151 \\
\hline alpha-Phellandrene & $\mathrm{C} 10 \mathrm{H} 16$ & 136.1252005 \\
\hline gamma-Terpinene & $\mathrm{C} 10 \mathrm{H} 16$ & 136.1252005 \\
\hline Longifolene & $\mathrm{C} 15 \mathrm{H} 24$ & 204.1878008 \\
\hline$(\mathrm{Z}, \mathrm{Z}, \mathrm{Z})$-Octadeca-9,12,15-trienoic acid & $\mathrm{C} 18 \mathrm{H} 30 \mathrm{O} 2$ & 278.2245802 \\
\hline Thymoquinone & $\mathrm{C} 10 \mathrm{H} 12 \mathrm{O} 2$ & 164.0837296 \\
\hline $\begin{array}{l}\text { Kaempferol 3-glucosyl-(1->2)-galactosyl-(1->2)- } \\
\text { glucoside }\end{array}$ & $\mathrm{C} 33 \mathrm{H} 40 \mathrm{O} 21$ & 772.2062083 \\
\hline Quercetin 3-glucosyl-(1->2)-galactosyl-(1->2)-glucoside & $\mathrm{C} 33 \mathrm{H} 40 \mathrm{O} 22$ & 788.201123 \\
\hline $\begin{array}{l}\text { Quercetin 3-(6"'--feruloylglucosyl)-(1->2)- } \\
\text { galactosyl-(1->2)-glucoside }\end{array}$ & $\mathrm{C} 43 \mathrm{H} 48 \mathrm{O} 25$ & 964.2484671 \\
\hline Fuzitine & $\mathrm{C} 20 \mathrm{H} 24 \mathrm{NO} 4$ & 342.1705333 \\
\hline Nigellicine & $\mathrm{C} 13 \mathrm{H} 14 \mathrm{~N} 2 \mathrm{O} 3$ & 246.1004423 \\
\hline Nigellidine & $\mathrm{C} 18 \mathrm{H} 18 \mathrm{~N} 2 \mathrm{O} 2$ & 294.1368278 \\
\hline Nigellimine & $\mathrm{C} 12 \mathrm{H} 13 \mathrm{NO} 2$ & 203.0946287 \\
\hline 4-Terpineol & $\mathrm{C} 10 \mathrm{H} 18 \mathrm{O}$ & 154.1357652 \\
\hline 4(10)-Thujene & $\mathrm{C} 10 \mathrm{H} 16$ & 136.1252005 \\
\hline Nigeglanine & $\mathrm{C} 12 \mathrm{H} 14 \mathrm{~N} 2 \mathrm{O}$ & 202.1106131 \\
\hline Nonane & $\mathrm{C} 9 \mathrm{H} 20$ & 128.1565006 \\
\hline Carvone & $\mathrm{C} 10 \mathrm{H} 14 \mathrm{O} 2$ & 166.0993797 \\
\hline alpha-Longipinene & $\mathrm{C} 15 \mathrm{H} 24$ & 204.1878008 \\
\hline Dihydrocarvone & $\mathrm{C} 10 \mathrm{H} 16 \mathrm{O}$ & 152.1201151 \\
\hline Nigellidine 4-O-sulfite & C18H18N2O5S & 374.0936424 \\
\hline
\end{tabular}


Table 2. Active compounds of Nigella sativa with antieczema affect.*

\begin{tabular}{lc}
\hline \multicolumn{1}{c}{ Active compounds } & Pa-value $^{* *}$ \\
\hline Oleic acid & 0.947 \\
\hline Lauric acid & 0.920 \\
\hline beta-Pinene (pinene***) & 0.902 \\
\hline Nonane & 0.895 \\
\hline Dihydrocarvone (trans-dihydrocarvone ${ }^{* * *}$ ) & 0.889 \\
\hline p-Cymene & 0.884 \\
\hline Estragol (estragole***) & 0.881 \\
\hline Longifolene & 0.878 \\
\hline alpha-Thujene (thujene***) & 0.866 \\
\hline gamma-Terpinene & 0.854 \\
\hline 4-Terpineol (terpinen-4-ol atau 4-carvomenthenol $* * *)$ & 0.838 \\
\hline Myrcene & 0.836 \\
\hline Carvacrol & 0.811 \\
\hline Myristicin & 0.795 \\
\hline Apiol (apiole***) & 0.794 \\
\hline Thymol & 0.788 \\
\hline alpha-Phellandrene & 0.772 \\
\hline Thymoquinone & 0.762 \\
\hline Carvone & 0.737 \\
\hline Available in STITCH data & Pa \\
\hline
\end{tabular}

* Available in STITCH database, predicted as antieczema, and Pa-value $>0.7$

** Probability of activity

*** Synonyms in STITCH and PubChem

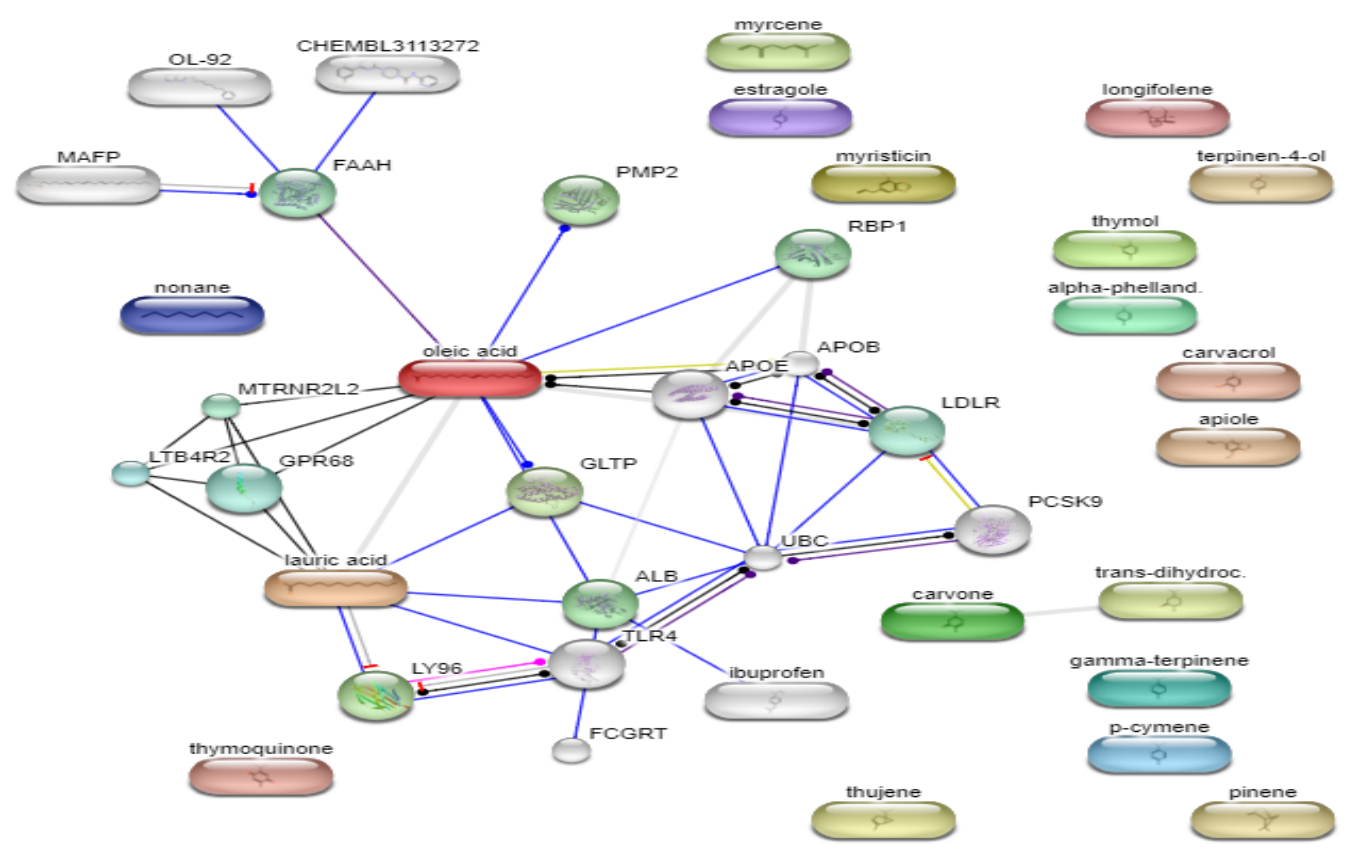

Figure 1. Interactomes of protein and chemical substances including active compounds of Nigella sativa. Color of lines denoted specific types of action, which were activation (green), binding (blue), phenotype (cyan), reaction (black), inhibition (red), catalysis (purple), posttranslational modification (pink), and transcriptional regulation (yellow). End shape of arrow denoted action effects, which were positive (triangle), negative (vertical line), and unspecified (round). 
Table 3. Gene ontology (GO) from interactomes involving oleic acid and lauric acid based on functional enrichment analysis.

\begin{tabular}{|c|c|c|c|c|}
\hline Gene ontology & Pathway identifier & Pathway description & Count in gene set & $\begin{array}{l}\text { False discovery } \\
\text { rate }\end{array}$ \\
\hline \multirow{10}{*}{$\begin{array}{l}\text { Biological } \\
\text { process }\end{array}$} & GO:0042159 & Lipoprotein catabolic process & 3 & 0.00491 \\
\hline & GO:0032805 & $\begin{array}{l}\text { Positive regulation of low density } \\
\text { lipoprotein particle receptor cata- } \\
\text { bolic process }\end{array}$ & 2 & 0.0176 \\
\hline & GO:0042632 & Cholesterol homeostasis & 4 & 0.0176 \\
\hline & GO:0001523 & Retinoid metabolic process & 4 & 0.0217 \\
\hline & GO:0034381 & Plasma lipoprotein particle clearance & 3 & 0.0217 \\
\hline & GO:0032497 & Detection of lipopolysaccharide & 2 & 0.0295 \\
\hline & GO:0007603 & Phototransduction, visible light & 4 & 0.0321 \\
\hline & GO:0008203 & Cholesterol metabolic process & 4 & 0.041 \\
\hline & GO:0006869 & Lipid transport & 5 & 0.0462 \\
\hline & GO:0008202 & Steroid metabolic process & 5 & 0.0462 \\
\hline \multirow{4}{*}{$\begin{array}{l}\text { Molecular } \\
\text { function }\end{array}$} & GO:0050750 & $\begin{array}{l}\text { Low-density lipoprotein particle re- } \\
\text { ceptor binding }\end{array}$ & 3 & 0.0118 \\
\hline & GO:0071813 & Lipoprotein particle binding & 3 & 0.013 \\
\hline & GO:0070326 & $\begin{array}{l}\text { Very-low-density lipoprotein particle } \\
\text { receptor binding }\end{array}$ & 2 & 0.0174 \\
\hline & GO:0001875 & Lipopolysaccharide receptor activity & 2 & 0.242 \\
\hline \multirow{4}{*}{$\begin{array}{c}\text { Cellular } \\
\text { component }\end{array}$} & GO:0034362 & Low-density lipoprotein particle & 3 & 0.0029 \\
\hline & GO:1990666 & PCSKg-LDLR complex & 2 & 0.0029 \\
\hline & GO:0046696 & Lipopolysaccharide receptor complex & 2 & 0.00579 \\
\hline & GO:0034363 & $\begin{array}{l}\text { Intermediate-density lipoprotein par- } \\
\text { ticle }\end{array}$ & 2 & 0.013 \\
\hline
\end{tabular}

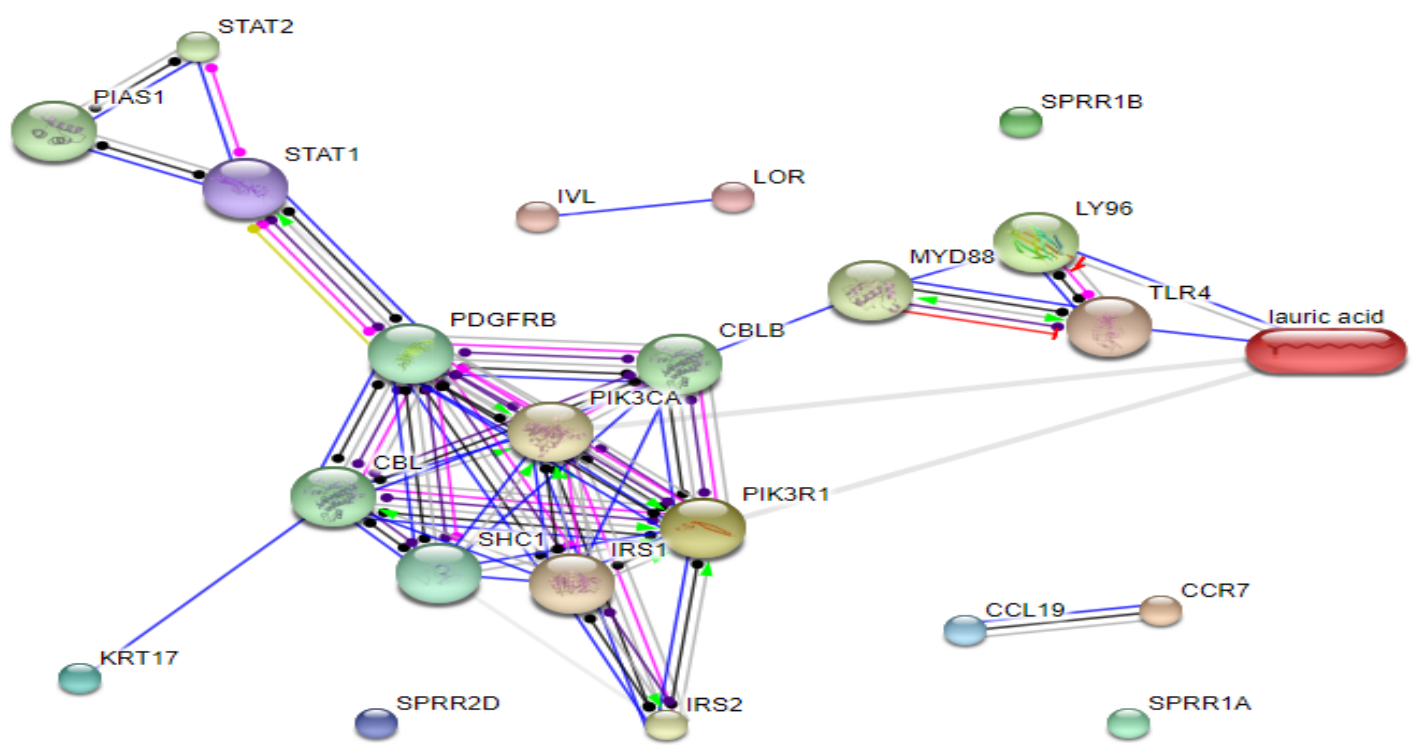

Figure 2 Interactomes of protein and chemical substances including ten gene names involved in AD along with LY96, TLR4 and lauric acid. Color of lines denoted specific types of action, which were activation (green), binding (blue), phenotype (cyan), reaction (black), inhibition (red), catalysis (purple), posttranslational modification (pink), transcriptional regulation (yellow), and unspecified (grey). End shape of arrow denoted action effects, which were positive (triangle), negative (vertical line), and unspecified (round). 


\section{Discussion}

Lauric acid was predicted having antieczema effect for $\mathrm{AD}$ with a plausible mechanism of action. It was indicated by interaction of lauric acid with LY96 and TLR4. Concurrently, both gene names were connected to PIK3R1 which was a part of interactomes involving proteins related to $\mathrm{AD}$. The GO information of these interactomes indicated that LPS was involved in antieczema mechanism of action for lauric acid as an active compound of $N$. sativa.

Topical administration of $N$. sativa seed's oil showed antieczema effect in patients who applied this oil twice a day for 28 days. The nineteen patients demonstrated lower hand eczema severity index (HECSI) compared to those eighteen patients given eucerin as negative controls $(\mathrm{P}=0.003)$. Likewise, the dermatology life quality index (DLQI) was also lower $(\mathrm{P}<0.0001)$. There was no difference with patients given betamethasone as positive controls for HECSI $(\mathrm{P}=0.99)$ or DLQI $(\mathrm{P}=0.38) .{ }^{4}$

Conversely, there was no difference in efficacy for twenty patients who applied the formulation of $N$. sativa oil on one hand and placebo on the other hand. The efficacy was no difference in terms of severity, pruritis, transepidermal water loss, and skin hydration. ${ }^{6}$ However, this might occur due to difference in composition of active compounds. It might also occur because of different composition of inactive compounds in the formulation.

The LY96 protein that binds to TLR4 as its receptor was connected to interactomes related to AD via MYD88. The interaction score of MYD88 with the interactomes was moderately significance. Clinical manifestations of patients with MYD88 gene deficiency indicated inflammation of the skin. The MYD88 protein is an adapter protein receiving signals from extracellular to intracellular proteins, particularly by binding CBLB in this study, a negative regulator of T-cell activation.

In turn, the CBLB protein was indicated by the pathway as a catalyzer for PIK3R1 as the downstream protein related to $\mathrm{AD}$, which encodes a regulatory subunit of phosphoinositide 3-kinase. ${ }^{12}$ The role of PIK3R1 in AD were investigated by few studies, ${ }^{13,14}$ indicating a potential novel target for AD treatment. This protein extensively interacted with other proteins, such as STAT1 that acts as a transcription factor involved in chemokine signaling pathway, including that in peripheral mononuclear cells of AD patients. ${ }^{15}$

Another protein, which is KRT17, was also connected with the extensive interactions involving PIK3R1. The gene of KRT17 was upregulated along with IVL in canine AD.16 The IVL expression demonstrated reduction of genes expression for proteins that maintain epidermal barrier, which were EGFR, e-cadherin, occludin, envoplakin, and periplakin. ${ }^{17,18}$

The inflammation of skin involving MYD88 was also due to infection by two opportunistic bacteria which were Staphilococcus aureus and Pseudomonas aeruginosa. ${ }^{10}$ Atopic dermatitis is a common skin disease involving microbial infection. This was shown by dominance of $S$. aureus, including those that were resistant to methicillin, like many Streptococcus sp. and P. aeruginosa. ${ }^{11}$ The antieczema effect may occur by increasing activity of these proteins to control opportunistic bacterial population by detection of LPS and activation of innate immunity. Inflammation allegedly persists for controlling opportunistic bacteria; thus, the severity of AD is reduced. Conversely, if opportunistic bacteria are out of control, more severe inflammatory response may occur. Eventually, this may prevent relapse occurrence in AD patients.

Our study presents prediction of pharmacological effect and pathway analysis that showed lauric acid contains in $N$. sativa has a potential role as antieczema to relieve inflammation in AD. Computer-aided prediction and the pathway analysis may save time for ligand-based drug discovery. This in silico analysis can be a starting point to conduct in vitro and in vivo testing.

However, computational prediction may possess a risk of bias. This depends on available datasets that were utilized to train the prediction model. Features of the chemical structure in active compounds of $N$. sativa may be unobserved in the datasets. This may increase false discovery rate of the prediction model.

\section{Conclusion}

Lauric acid, via LY96-TLR4-PIK3R1 pathway, was found to be potential target to prevent relapse in AD patients. Topical administration of $N$. sativa seed's oil may be more acceptable in several cultures in Indonesia. However, prevention of relapse still requires further investigation to prove the efficacy to prevent $\mathrm{AD}$ relapse as well as toxicity testing for chronic administration.

Further computational investigation will be an analysis of potential binding site for lauric acid to the corresponding proteins. Affinity of the active compounds will determine its feasibility for wet laboratory testing. This study may help to estimate proper dosage for preclinical study.

\section{Conflict of Interest}

The author stated there is no conflict of interest

\section{References}

1. Mosquita KC, Igreja ACSM, Costa IMC. 2013. Atopic dermatitis and vitamin D: facts and controversies. An Bras Dermatol; 88(6): 945-53.

2. Deckers, I. A. G., McLean, S., Linssen, S., Mommers, M., van Schayck, C. P., Sheikh, A. 2012. Investigating international time trends in the incidence and prevalence of atopic eczema 1990-2010: a systematic review of epidemiological studies. PloS One, 7(7), e39803.

3. Yousefi, M., Barikbin, B., Kamalinejad, M., Abolhasani, E., Ebadi, A., Younespour, S., Hejazi, S. 2013. Comparison of therapeutic effect of topical Nigella with Betamethasone and Eucerin in hand eczema. JEADV, 27(12), 1498-1504.

4. Ahmad, A., Husain, A., Mujeeb, M., Khan, S. A., Najmi, A. K., Siddique, N. A., Anwar, F. 2013. A review on therapeutic potential of Nigella sativa: A miracle herb. Asian Pacific Journal of Tropical Biomedicine, 3(5), 337-352.

5. Razavi, B. M., Hosseinzadeh, H. 2014. A review of the effects of Nigella sativa L. and its constituent, thymoquinone, in metabolic syndrome. Journal of Endocrinological Investigation, 37(11), 1031-1040.

6. Stern, T., Bayerl, C. 2002. [Black Seed Oil Ointment - A New Approach for the Treatment of Atopic Dermatitis?]. Aktuelle Dermatologie, 28(3), 74-79.

7. Brandt, E. B., Gibson, A. M., Bass, S., Rydyznski, C., Khurana Hershey, G. K. 2013. Exacerbation of allergen-induced eczema in TLR4- and TRIF deficient mice. Journal of Immunology (Baltimore, Md. : 1950), 191(7), 3519-3525.

8. Augustin, M., Radtke, M. A., Glaeske, G., Reich, K., Christophers, E., Schaefer, I., Jacobi, A. 2015. Epidemiology and Comorbidity in Children with Psoriasis and Atopic Eczema. Dermatology, 231(1), 35-40. 
9. Zhang, Z.-K., Yang, Y., Bai, S.-R., Zhang, G.-Z., Liu, T.-H., Zhou, Z., He, S.X. 2014. Screening for key genes associated with atopic dermatitis with DNA microarrays. Molecular Medicine Reports, 9(3), 1049-1055.

10. Picard, C., von Bernuth, H., Ghandil, P., Chrabieh, M., Levy, O., Arkwright, P. D.,Casanova, J.-L. 2010. Clinical Features and Outcome of Patients With IRAK-4 and MyD88 Deficiency. Medicine, 89(6), 403-425.

11. Higaki, S., Kitagawa, T., Kagoura, M., Morohashi, M., Yamagishi, T. 2000. Predominant Staphylococcus Aureus Isolated from Various Skin Diseases. Journal of International Medical Research, 28(4), 187-190.

12. Parvaneh, N., Casanova, J.L., Notarangelo, L.D., Conley, M.E. 2013. Primary immunodeficiencies: a rapidly evolving story. Journal of Allergy and Clinical Immunology, 131:314-323.
13. Watanabe, O., Tamari, M., Natori, K., et al. 2001. Loci on murine chromosomes 7 and 13 that modify the phenotype of the NOA mouse, an animal model of atopic dermatitis. Journal of Human Genetics, 46:221-224.

14. Heinzmann, A., Daser, A. 2002. Mouse models for the genetic dissection of atopy. International Archive of Allergy and Immunology, 127:170-180

15. Heishi, M., Kagaya, S., Katsunuma, T., et al. 2002. High-density oligonucleotide array analysis of mRNA transcripts in peripheral blood cells of severe atopic dermatitis patients. International Archive of Allergy and Immunology, 129:57-66.

16. Theerawatanasirikul, S., Sailasuta, A., Thanawongnuwech, R., Suriyaphol, G. 2012. Alterations of keratins, involucrin and filaggrin gene expression in canine atopic dermatitis. Research of Veterinary Science, 93:1287-1292. 